results of a detailed study of the weathering status and mineralogy of podzolic soils in the Barossa Valley in South Australia.

On the first evening of the meeting Prof. Zeuner delivered an address on "Soils and Shore Lines as Aids to Chronology" and emphasized the significance of changing sea-levels. He illustrated his address by examples from numerous localities, including especially the Jebel Druz in northern Arabia, where the qa depressions and their shore-line features have proved a profitable source of chronological data, and from the Arabs Gulf on the coast of Egypt, where a series of stranded bar beaches and lagoons strikingly similar to those in the south-east of South Australia has likewise yielded data on former high sea-levels. On the second evening Prof. Tricart spoke on the use of geomorphological maps in the field of pedology. $\mathrm{He}$ illustrated his paper by reference to studies of landforms in the headwaters of the Niger River, and in the lower situated inland delta of the same river near Timbuktu, where irrigation works were planned, also from the Senegal delta, where two old dune systems have in recent times been subject to partial marine inundation.

The last formal session on December 7 was devoted to recommendations arising from the symposium. Four resolutions were passed: (1) suggesting a standing committee on quaternary research to arrange symposia and advise on the use of any funds available; (2) emphasizing the need for greater organized effort in the compilation of topographic maps; (3) suggesting that active field workers be encouraged to attend international conferences concerned with Quaternary chronology; (4) proposing that a register of Australian radiocarbon and other datings be kept. These resolutions have been forwarded to the Aus. tralian Academy of Science and were reported in detail to the Third Australian Conference in Soil Science held in Canberra in February.

The last day of the symposium, December 8, was devoted to a field excursion led by Mr. W. T. Ward to the coastal area immediately south of Adelaide. Here the tilted fault blocks of the Mount Lofty Ranges meet the coast at St. Vincent Gulf and for some distance inland at various elevations show a number of bevelled surfaces of marine origin. One surface, $520 \mathrm{ft}$. above sea-level, preserves a cobble beach which has been the site of the manufacture of aboriginal stone implements. The oldest of the surfaces has a variable cover of fine-to-medium textured æolian material presumably derived by wind erosion of the exposed floor of St. Vincent Gulf in times of glacial low sealevel. The different base-levels of erosion created by changes in sea-level have controlled deposition in streams graded to those levels, and the deposited materials exhibit a sequence of soils whose morphology is related primarily to age. With increasing age there is greater textural differentiation, increasing development of gilgai, and greater degradation of the soil profiles.

During the symposium a collection of photographs, colour slides, soil profiles and specimens from a number of pedological and geomorphological studies by the Division of Soils was arranged and exhibited by Mr. H. C. T. Stace.

The proceedings of the symposium will not be published, but a mimeographed record of the papers, lectures, discussions and resolutions will be prepared by the Australian Academy of Science. It is anticipated that the substance of many of the papers will be published eventually in the usual journals.

\section{G. STEPHENS}

\title{
FIRST BIOMAGNETIC SYMPOSIUM
}

$\mathrm{D}$ URING November 24-25, the first Biomagnetic Symposium was held in the College of Pharmacy, University of Illinois. The symposium, organized by Madeleine F. Barnothy, included three sessions of contributed papers and the visit to three magnetobiological laboratories in the Chicago area. Sixtyfive persons from all over the United States attended the meeting. The aim of the symposium was to bring together persons interested in this new field of research, to try to clarify the mechanism through which magnetic fields produce biological effects and to report about new experimental findings.

After the welcoming address of George L. Webster, dean of the College of Pharmacy, the first session was devoted to the fundamental phenomena which may occur under the influence of magnetic fields in biological systems. Jeno M. Barnothy (Biomagnetic Research Foundation, Evanston) discussed the physical effects caused by homogeneous and inhomo. geneous magnetic fields on para- and dia-magnetic molecules and on systems in which thermal or electric currents and/or gradients exist. $\mathrm{He}$ stressed the importance of the recognition that magnetic field and gradient are vector quantities, whereby a motion of the biological specimen during exposure time with respect to these vectors could tend to annul cumulative effects. He discussed the rejection and complete healing he observed on $T 2146$ and $H 2712$ implanted tumours in mice and the arrest of the growth of the spontaneous mammary gland carcinoma of the $C 3 H$ strain. He attributes tumour healing mainly to the general retardation of mitosis in magnetic fields, although in case of transplanted tumours an enhancement of the homograft reaction of the host cannot be excluded. He demonstrated sections of the spleens of magnetically treated mice which showed in 90 per cent of the investigated cases a proliferation of the white pulp and replacement of the spleen substance with immature looking lymphoblasts. Two papers by M. Valentinuzzi (National Institute of Microbiology, Argentina) and L. N. Mulay (University of Cincinnati) dealt with the chemical effects caused by magnetic fields in biological systems. Valentinuzzi stressed the change in reactionrate and change in concentration due to the motion of para- and dia-magnetic particles along magnetic gradient. Mulay discussed ferro- and anti-ferromagnetic interactions and the importance of polymeric co-ordination compounds.

The first afternoon session opened with the paper of L. J. Audus and J. Wish (Bedford College, London), which discussed experiments on magneto-tropism of plants. They found a growth-curvature of seedling roots and shoots down the magnetic gradient, but could not verify their assumption that the curvature was caused by migration of gravi-sensitive starch grains. H. S. Alexander (North American Aviation Corp.) reported on some inhibition observed on barley seeds. V. Gerencser (University of West Virginia) and M. F. Barnothy (University of Illinois) described 
the inhibition of the growth of Serratia marcescens and Staphylococcus aureus cultures after $5-6 \mathrm{hr}$. in a strong inhomogeneous magnetic field. The shape of the growth-curve supports the view that after $6 \mathrm{hr}$. exposure to the magnetic field only a magnetic. ally resistant strain of the population multiplies further. I. L. Mulay (Cincinnati) reported on body deformations found on first and second generations of Drosophilia melanogaster grown in magnetic fields, suggestive of genetic changes. Sarcoma 37 ascites tumour cells, grown in hanging-drop cultures, showed after $18 \mathrm{hr}$. exposuro complete cell degeneration. The last two papers of this session, by F. A. Brown and F. H. Barnwell (North-western University, Evanston), were devoted to effects of very weak magnetic fields on the orientation of snails, planarians and fruit flies.

On the next day D. C. Butler and D. W. Dean (Butler Research Foundation, Phoenix, Arizona) reported on inhibitory effects observed in the genera. tion of K.B. cells. Leo Gross (Waldemar Medical Research Foundation, Port Washington, New York) discussed his results on the inhibition of transplanted tumours in animals treated prior to implanta. tion in magnetic ficlds. He attributes this effect to the lymphocytosis ensuing magnetic treatment (Nature, 177, 577, 1956). In his experiments on wound healing in magnetic fields he found as much as 20 per cent delay in the reparative process. He discussed also his present investigations on an antibody titre mothod, as well as his theory that the effect of magnotic fields is due to the infiuence of the enzyme substrate intermediates, which are, during their short existence, in the form of free radicals. The last paper, by M. W. Freeman and J. H. Watson (Detroit), described means of introducing iron into the vascular system with the help of sublingual application of iron erystals.

The sessions were concluded by very lively general discussions in which new avenues of approaches and new interpretation possibilities were proposed. On the first day the participants visited the biomagnetic laboratory of the College of Pharmacy, University of Illinois, where a Varian 4-in. electromagnet is available with special pole caps and thermostat facilities to examine the effects of vory strong hemegenocus and inhomogeneous magnotic fields on bacterial cultures, tissue cultures, oxygen ensiumption of plants and animals and localized treatment of spontaneons tumours in mice. On the second afternoon the group visited first the laboratory of F. A. Brown at North-western Univorsity, where orienta. tion of snails, Planaria, etc., are investigated in very woak fields. Thereafter, they visited the laboratory of J. M. and M. F. Barnothy at the Biomagnetic Research Foundation in Fvanston. Here. ton large pormanent magnots are insialled in which 30 mice can be treated at the same time for prolonged periods and whore many of the so far established biomagnetic effocts were discoverod (effect on leucocyte count, retardation of dovelopment of embryos and younc animals, postponement of ageing and of the inset of spontaneous cancers, compensation of radiation syndromes. ete.). M. F. BARNOTHY

\section{BRITAIN'S WATER PROBLEM}

A $\mathrm{N}$ indication of the welcome increase of interest in the growing water problems of Britain (to which Nature has frequently made reference during tho past decade ${ }^{\mathrm{T}}$ ) has recently been domonstrated by the rapid sale of the final survey of the Sub-Committee on the Growing Demand for Water. This latest report ${ }^{2}$ of the Central Advisory Water Committee was sold out on publication and is now being reprinted.

The report may prove to be one of the most significant that has yet come from the Central Advisory Water Cornmittee as it proposes a major reorganization of Britain's water resources along the lines of the momorandum which was circulated by the Minister of Housing and Local Government in the spring of 1961 (ref. 3). The Sub-Committee recognizes that numerous interests are at present engaged in activities which affect the quantity and quality of water available. The authorities range from the Minister of Housing and Local Government to the Minister of Agriculture, Fisheries and Food, and from the River Boards, Internal Drainage Boards, statutory water undertakers, navigation and public health authorities, to agricultural, industrial and riparian interests. There is at present little or no co-ordination between many of these bodies and some indeed work against each other. No single authority is rosponsible locally for determining the proper use and development of the water resources, and there is no machinery for planning and executing positive conservation measures, either locally or nationally. The Sub-Committee thinks that the time has now come when a major reorganization must bes attempted to meet the increasing demands on Britain's water resources. As the river basin is the natural hydrological unit the recommendation is made that new authorities should be set up to administer river basins and that these should be co-ordinated by at central authority accountable to the Minister.

The proposed now bodies are termed "River Authorities" in the report and it is envisaged that they would be charged with the positive duty of water conserva. tion. This is defined as "the preservation, control and development of water resources (both surface and ground) by storage and other means, and the prevention of pollution, to ensure that the largest possible amount of water is made available for all purposes in the most suitable and economical way whilst safeguarding legitimate interests". The River Authorities would be required to assess the water resources of their areas, and where appropriate develop those rosources. On the position of the existing statutory water undertakers the report recommends that "The question whether storage for public wator supply should be provided by, or jointly with, the river authorities, or by statutory water undertakers alone, will be a matter for agreement. Once this has been determined and the quantity, point and method of abstraction, including the building of reservoirs, have been settled, the impounding, abstraction, treatment and distribution of the water for the public supply should remain entiroly the responsibility of the statutory water undertakers".

As part of the policy of water conservation it is envisaged that River Authoritios would construct and operate river regulating and other reservoirs according to need, and where appropriate transfer water from one basin to another. The Sub-Committee 